\title{
Petroleum Sciences \\ A statistical solution for cost estimation in oil well drilling
}

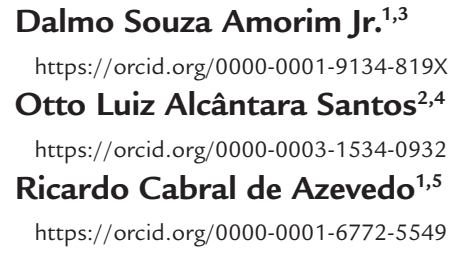

${ }^{1}$ Universidade de São Paulo - Escola Politécnica, Departamento de Engenharia de Minas e Petróleo São Paulo - São Paulo - Brasil.

${ }^{2}$ Louisiana State University,

Baton Rouge - United States

E-mails: ${ }^{3}$ dalmo.amorim@gmail.com, ${ }^{4}$ ottolasantos@gmail.com, ${ }^{5}$ rcazevedo@usp.br

\begin{abstract}
Drilling operations must be preceded by adequate planning, fulfilling the path to produce hydrocarbons at low and competitive costs. Conventional well planning is based on the personal experience of project engineers, which use information from offset wells to estimate the performances in future wells. This article reviews and discusses a published statistical methodology for planning upcoming oil wells. The statistical approach incorporates uncertainties of the process, reducing the relevance of personal decisions and supporting the staff with more realistic cost estimations. A reliable project can reduce unexpected expenditures in a long-term campaign and shorten the learning time, resulting in improved cost prediction and a better-fitted calendar. An expressive database, containing information from an onshore field in Brazil, yields a case study to demonstrate the benefits of this approach for the development of new drilling projects. The solution presented supports a more precise planning of costs, the improvement of technical limits and the development of different technologies in drilling operations in future wells.
\end{abstract}

Keywords: geosciences; cost per meter; least squares; Amorim curve.

\section{Introduction: Drilling a well}

Drilling bits are used until the moment they wear out and become ineffective, being pulled out of the well and replaced by a new one. At the end of a section, the bit connected to the bottom end of the drill string is pulled out from the hole, being a casing string run and cemented. Drilling will continue until the production zones are reached, when they are abandoned or completed to start producing. Some wells are drilled with the casing itself replacing the conventional

\subsection{Planning a drilling campaign}

The preparation of a drilling program is performed by experienced people, being desirable knowledge about the area of the upcoming wells. A project engineer analyzes geological information (Bera, 2010) and operational data from offset wells (Simmons, 1986), estimating future performances of the drilling operations based on existing drill string, disclosed as economic by saving time circulating, running casing and reducing non-productive time (Patel, D. et al, 2018).

The operational information of the wells is registered in a Bit Record. Its heading includes name of field and well, spud-in date, operator and relevant rig information. Each line contains the unique information that specifies each bit: serial number, running sequence, pullout date and depth, bit type and diameter, length

information and personal knowledge.

Traditionally, the poor bit performances are discharged, understood as being the result of bad practices that shall not be repeated. A handful of good runs are elected as results to be repeated or improved. As the dataset used in a conventional analysis (Devore, 2010) is different from a statistical set, since drilled, rig hours and rate of penetration. Additional space is included for the eight IADC codes to report the bit wear and remarks (McGehee, D.Y. et al., 1992), inclination of the well, size of jet nozzles, drilling parameters and some mud properties. Unfortunately, a most desirable Increase in Cost per Meter IADC code was not included in the IADC 1992 reviews to report that a bit had become economically inefficient (Brandon, B.D. et al., 1992), needing to be replaced.

only some good drilling performances are considered in the former approach, uncertainty is brought to the costs of the future wells.

Intervals of the planned well are divided by the expected rate of penetration (ROP) by depth, generating the Drilling Hours seen in a Bit Program (Table 1). 


\begin{tabular}{c|c|c|c|c|c|c|c|c|c|c|c|c} 
Bit & Section & Bit & Bit & Depth & Length & Drilling & ROP & Acc. & WOB & RPM & Mud & Remarks \\
\hline $\mathbf{n}^{\circ}$ & $\mathbf{n}^{\circ}$ & size & type & Out & Drilled & Hours & - & Hours & - & - & Weight & - \\
\hline- & - & (in) & - & $(\mathrm{m})$ & $(\mathrm{m})$ & $(\mathrm{h})$ & $(\mathrm{m} / \mathrm{h})$ & $(\mathrm{h})$ & (ton) & - & $(\mathrm{sg})$ & - \\
\hline 1 & 1 & 26 & 115 & 1000 & 950 & 60 & 15.8 & 60 & $6-15$ & $80-140$ & 1.2 & IADC 115 \\
\hline 1 & 2 & $17.1 / 2$ & 115 & 2100 & 1100 & 110.0 & 10.0 & 110 & $10-18$ & $120-160$ & 1.4 & IADC 115 \\
\hline 2 & 2 & $17.1 / 2$ & 115 & 3300 & 1200 & 120.0 & 10.0 & 230 & $10-15$ & $80-160$ & 1.5 & IADC 115 \\
\hline 3 & 3 & $14.3 / 4$ & PDC & 4150 & 850 & 100.0 & 8.5 & 330 & $2-3$ & $120-130$ & 2.0 & Bicenter Bit \\
\hline 4 & 3 & $14.3 / 4$ & PDC & 4500 & 350 & 33.0 & 10.6 & 363 & $2-3$ & $120-130$ & 2.0 & Pilot bit 8.5 \\
\hline 5 & 4 & $12.1 / 4$ & PDC & 5260 & 760 & 95.0 & 8.0 & 458 & $2-4$ & $80-120$ & 1.9 & Pilot bit 8.5 \\
\hline 6 & 4 & $12.1 / 4$ & PDC & 5370 & 110 & 30.0 & 3.7 & 488 & $3-5$ & $70-100$ & 1.9 & Pilot bit 8.5 \\
\hline 7 & 4 & $12.1 / 4$ & PDC & 5500 & 130 & 35.1 & 3.7 & 523 & $3-5$ & $70-100$ & 1.9 & Pilot bit 8.5 \\
\hline 8 & 5 & $8.1 / 2$ & 537 & 5610 & 110 & 70.0 & 1.6 & 593 & $8-10$ & $80-100$ & 1.0 & Metal seals \\
\hline 9 & 5 & $8.1 / 2$ & 537 & 5720 & 110 & 70.0 & 1.6 & 663 & $8-10$ & $80-100$ & 1.0 & Metal seals \\
\hline 10 & 5 & $8.1 / 2$ & 517 & 5830 & 110 & 70.0 & 1.6 & 733 & $6-8$ & $80-100$ & 1.0 & Metal seals \\
\hline 11 & 5 & $8.1 / 2$ & 517 & 5940 & 110 & 70.0 & 1.6 & 803 & $6-8$ & $80-100$ & 1.02 & Metal seals \\
\hline 12 & 6 & 6 & 517 & 6090 & 150 & 90.0 & 1.7 & 893 & $4-6$ & $80-100$ & 0.67 & Metal seals \\
\hline 13 & 6 & 6 & 517 & 6237 & 147 & 90.0 & 1.6 & 983 & $4-6$ & $80-100$ & 0.67 & Metal seals \\
\hline 14 & 6 & 6 & 517 & 6384 & 147 & 90.0 & 1.6 & 1073 & $2-5$ & $80-100$ & 0.67 & Metal seals \\
\hline 15 & 6 & 6 & 517 & 6531 & 147 & 90.0 & 1.6 & 1163 & $2-5$ & $80-100$ & 0.67 & Metal seals \\
\hline & & & & & & & & & & & &
\end{tabular}

Fixed costs: expenditure with inventory of replacement parts, wellhead elements etc. are predictable and have negotiable prices. Some costs are related to the measured depth, such as the cost of casing string, volumes of cement slurries, mud additives, time to log, run casing and wait for cement hardening. Most of the variable costs that compose CAPEX (capital expenditure) are predictable within good precision by using statistical models developed for the petroleum industry (Samuel, 2010).

Variable costs: can be significantly affected by variations in the drilling

\subsection{Pros and cons of each method}

A great advantage of the conventional planning process is that the experience of the project engineer can overcome poor data or lack of information. However, all useful information should be included in a larger database so that the proper statistical analysis is made. "Being able to effectively organize and categorize information will ultimately deliver more intelligence into the business by enabling better and faster decision-making" (Stevens, 2016).

speed, non-productive (NPT) and lost time (York, et al., 2009). Since time estimations for the OPEX (operational expenditure) are mostly based on personal experience, different results can be expected from different project engineers. In a conventional planning, where only good results of the offset wells are selected and the poor runs rejected, costs might end up higher than planned. Imprecision can significantly influence the variable costs of a well, especially considering that rig costs can escalate to US $\$ 1,000,000 /$ day.

Drilling bit manufacturers and

In the authors' view, some weaknesses of the conventional process are:

- The performances of the best bits are analyzed, instead of their costs per meter;

- Marketing might affect the selection of more conservative and adequate options;

- Development of technology is affected by enthusiasm and prices, not costs;

- Restrictions from management might result in purchasing of bits of low price;

\section{Materials and methods: a statistical approach for well planning}

This article discusses a solution published in a thesis in 2008 (Amorim Jr., D. 2008), developed to mathematically estimate the cost of any interval drilled in an oil well, and updates the Case Study of the thesis. The research started in 1985, plotting operational results in paper, being later improved with Lotus 1-2-3 and Excel.

Conceived to be a statistical approach to increase the reliability of drilling operations, it has demonstrated to be
Table 1

Example of a proposed Bit

Program for an onshore well in Mexico.

tool rental companies, willing to sell or rent their products and beat competitors, will propose the least expensive solutions that match the estimations made in the proposed well program. Marketing and the desire to improve performances influence the process, sometimes generating objectives of low probability to happen or even to be repeated in a same field. Imprecise projections will also affect the logistics of subsequent wells in a drilling campaign, resulting in additional standby fees of tools and equipment, anticipation of purchases and potential hurried orders.

- Neglected poor performances represent an obstacle to knowing which needed bit protection has failed, or was insufficient, to face the challenges;

- Projections vary significantly, depending on the experience and optimism of the project engineer;

- Risk analysis normally is not shared, being delegated to an independent process;

- More backup bits are needed to comply with uncertainties.

ded by hard shale and limestone layers, seen in Figure 1, demand special features and protections to be used at the drilling bits. In a challenging environment, where wells can surpass $5,000 \mathrm{~m}$ of measured depth, the quest for long bit runs is mostly desired to reduce drilling costs. An extensive database of 1164 bit runs from 138 wells, drilled from 1981 to 2010, was used to produce the Amorim Curve (Amorim Jr., D., 2008) shown in Figure 5. 
Figure 1

Geological profile of Pilar field, 2003. Source: ANP.

\subsection{Collecting and organizing data}

The first step of the well planning discussed is to survey all existing information related to the drilling operations in that field. Data is organized in a spreadsheet and duplicate entries

where: $\mathbf{C M}$ is the cost per meter at the depth that the bit was pulled; (US\$/m), CB is cost of the bit; (US\$), $\mathbf{C H}$ is cost of the drilling operation per hour; (US\$ $/ \mathrm{h})^{2}$, TT is the time spent in a round trip to replace the bit; $(\mathrm{h})^{3}$, HR represents time spent in the drilling operation; $(h)^{4}, \mathbf{M D}$ is the length drilled by the bit; (m).

${ }^{1}$ Bits using additional protection or better technology are more expensive and might be used multiple times. MD is adjusted after new runs are made; the bit cost is shared with the total length drilled, modifying the Amorim curve in the optimization process. The conventional calculation of CM using $100 \%$ of CB in first run does not reflect the true costs of developing new technologies.

${ }^{2} \mathrm{CH}$ must include cost of rig, tools, logistics, diesel, standby of equipment, office support and any cost that would not exist if the drilling process was not taking place. Conventional calculations underestimate $\mathrm{CM}$ by using only rig rental

\subsection{Preparing the database}

As the drilling operations go on, it is ideal that the CM be calculated and the chart updated, shown in Figure 2. It

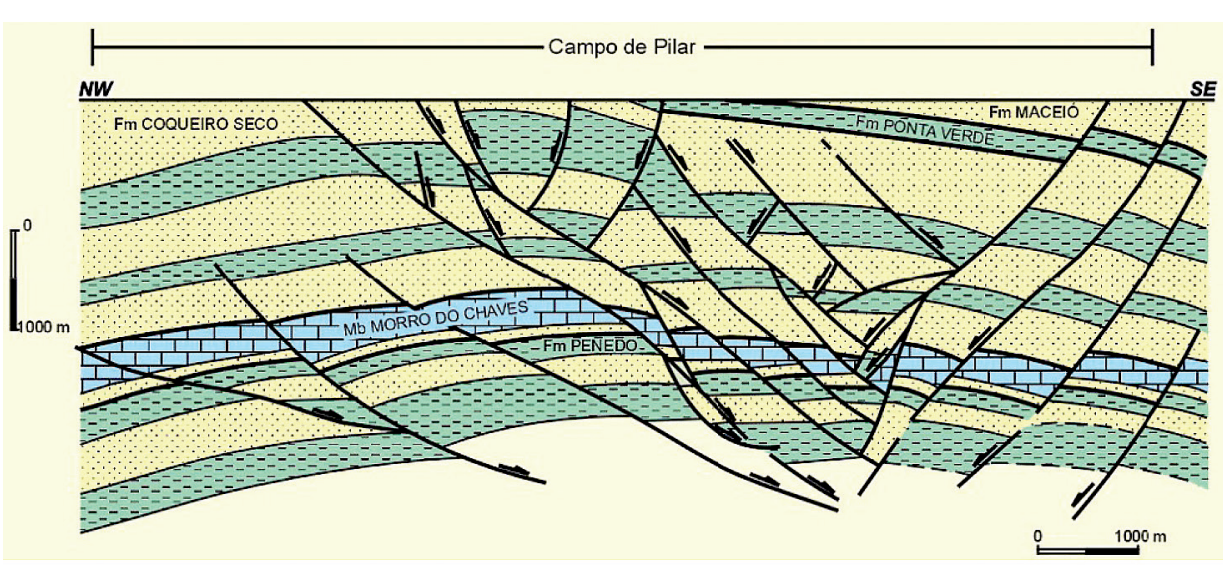

are disregarded. The key indicators of the process, tied to a date, are the bit serial number and bit running order in that well. The cost per meter (CM) is the variable modeled in the optimiza-

$$
C M=\frac{C B+C H \times(T T+H R)}{M D}
$$

tion process, intending to predict and to minimize drilling costs of any upcoming well. The traditional formula for cost per length for any bit run is used to calculate the CM (Eq. 1):

and diesel costs.

'TT: the trip time has been traditionally estimated as a linear function of DO (Depth Out): TT=0.003 $\times$ DO +1 (Amorim Jr., D. \& Iramina, W., 2008). TT can be adjusted by linear regression using actual rig data (Lee, S.S. et al., 2018).

${ }^{4} \mathrm{HR}$ registered in Bit Records has embedded time spent in drilling, connections and quick repairs. The usage of the true drilling time in the process introduces a difficulty of surveying data, but it is a most valuable refinement to the optimization process.

The cost per meter achieved at the end of each bit run is a non-linear and non-stochastic event (Van Kampen, 1992), affected by the well depth and complex aspects:

In deeper wells, the trips to replace bits are longer, more complex and should be minimized by longer bit runs (Kaiser, 2009);

A progressive and variable increase in non-linear rock strength, that

initially presents a quick decay - as the cost of the bit is still being shared by a shorter extension drilled, slowly stabiliz- reduces the rate of penetration and demands increasing drilling energy levels (Barton, 1976);

Underbalanced and overbalanced mud weights affect the rate of penetration (Bjelm, 2006);

Abrasiveness is a non-linear factor that accelerates dulling of cutters, increasing the number of trips and trip length per run (Grimes et al., 2007);

Pipe addition increases the elasticity of the drill string, slowly changing its resonance modes and modifying the drilling efficiency (Christian, 2017). A negative scenario of drilling vibrations will affect the number of trips, increase the drilling hours, accelerate bit wear and reduce the length drilled per run (Amorim, et al., 2012);

Certain well trajectories increase the total area of the elements of drill string contacting the walls, with significant increment in friction, reduction in drilling efficiency and rates of penetration (Ghasemloonia, A., 2012).

ing. The objective of this procedure is to minimize the $\mathbf{C M}$, pulling the bit at its minimum drilling cost:

$$
\frac{d C M}{d C D}=0 \text { or } C M=C M_{m i n} \text {, which occurs when } C M<C M_{n+1}
$$

Such an economical flag cannot be strictly taken into consideration to pull a bit as $\mathbf{C M}_{n+1}$ is calculated only if an additional length is drilled. If $\mathbf{C M}_{\text {min }}$ has been achieved but drilling continues, the overall cost of the section (Eq. 2) will gradually increase. As the CM is increasing, improvements in ROP are needed to justify maintaining the present bit at the bottom. Other actions are then taken: check the drilling parameters, lithology changes and mud conditions; and 
perform an evaluation of the total cost of drilling over the remaining length by

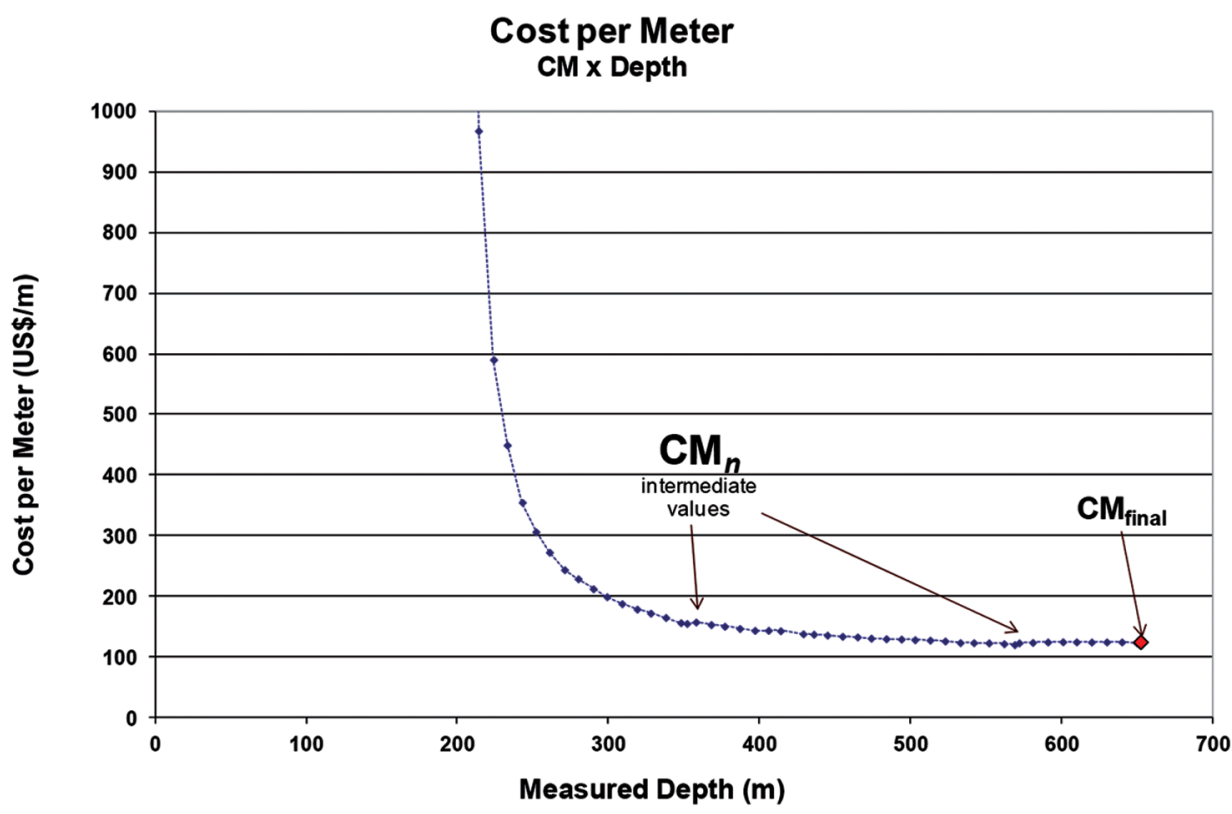

In Figure 2 a small increase in the $\mathrm{CM}$ is seen at $350 \mathrm{~m}$, but drilling continued; $\mathrm{CM}_{\min }$ was achieved at 570 $\mathrm{m}$, but the bit was replaced only at
$650 \mathrm{~m}$. The well continued after the replacement of the first bit, such that two more bits were needed to reach the total depth of the section. The cost of running a new bit.
Figure 2

Cost per meter calculations performed until the bit was pulled.

the section is the sum of the $\boldsymbol{n}$ operational costs, expressed by Formula 2 and represented in Figure 3 by the sum of the shaded areas:

$$
\begin{gathered}
\text { CostSection }=C M_{1} \times M D_{1}+C M_{2} \times M D_{2}+\ldots+C M_{n} \times M D_{n} \\
\text { CostSection }=\int_{\text {Depthln }}^{\text {DepthOut }} C M_{i} \times M D_{i}=\sum C M_{i} \times M_{i}
\end{gathered}
$$

\section{Results: estimating operational results}

When planning a new well, predicting the value of $\mathbf{C M}$ versus depth is almost a guess exercise. In the chart of the CM for the Pilar field, shown in Figure 4, it is noticeable that for depths less than $2000 \mathrm{~m}$, the dots are concentrated under the value of US $\$ 200 / \mathrm{m}$. In the conventional plan-

\section{CM x Depth Out}

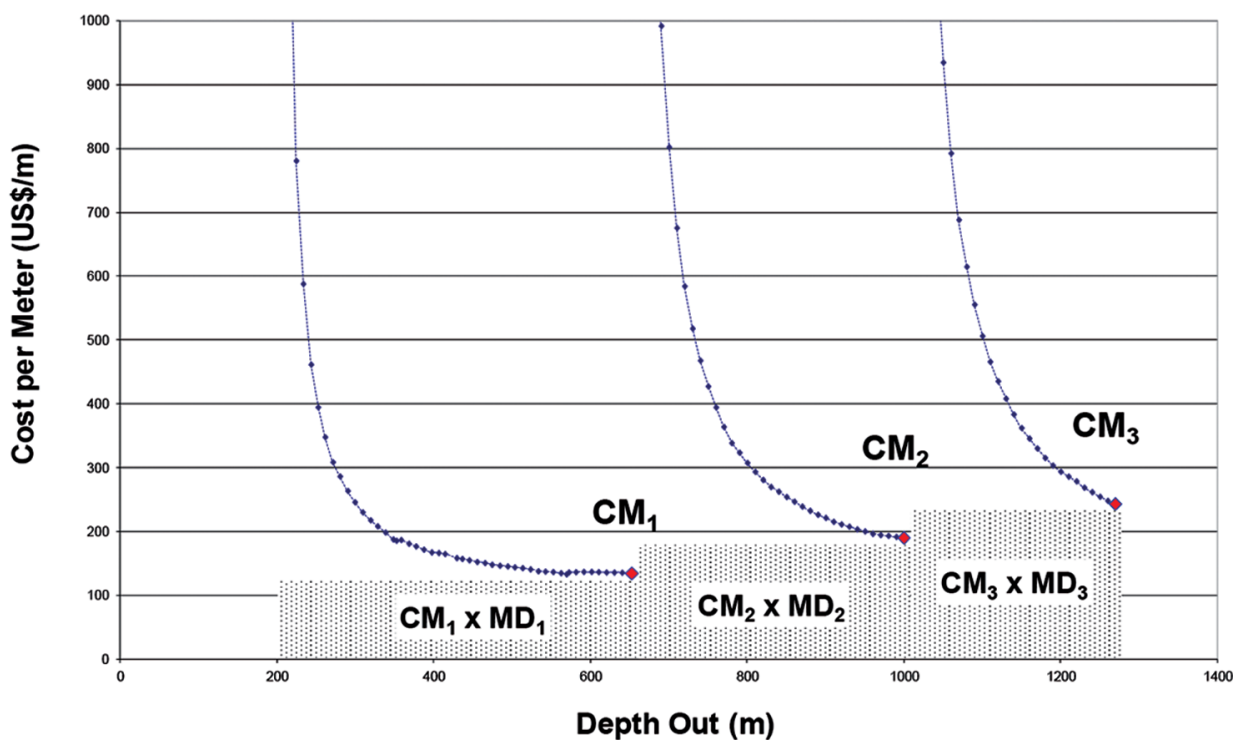

It is noticeable that the vertical spreading of $C M$ is different in function of the well depth. Drilling costs are the result of crossing different geological ning process, the project engineer will pick an average of a couple of good runs, hoping they are repeated during the drilling operations.
Figure 3

Total cost of the section for the three bits used in a section.

formations, trouble zones and of overcoming operational hazards (York, et al., 
2009), unique in each field. This is a solid argument against the usage of averages to plan future performances.

Risk will be reduced in proportion to how close the points are about the curve in a determined depth (Devore, 2010). The distribution in the $\mathbf{y}$-axis, shown by the arrow in Figure 4 is a useful estimation of risk, illustrating the chances of not repeating planned per- formances: around $4000 \mathrm{~m}$ the dots are less spread and more likely are the chances to achieve similar performances; the opposite is expected in the range of $2500-3000 \mathrm{~m}$.

\section{CM x Depth Out}

Figure 4

Plotted $\mathrm{CM}$ values of all bit runs in Pilar field.

\subsection{Cost of any section or interval}

The principle of least squares, developed by the German mathematician Carl Friedrich Gauss (1777-1855), is used to treat the database, representing an evolution to the conventional planning procedure, which selects

The regression that best fits the deterministic values (Freitas, 2003) will be

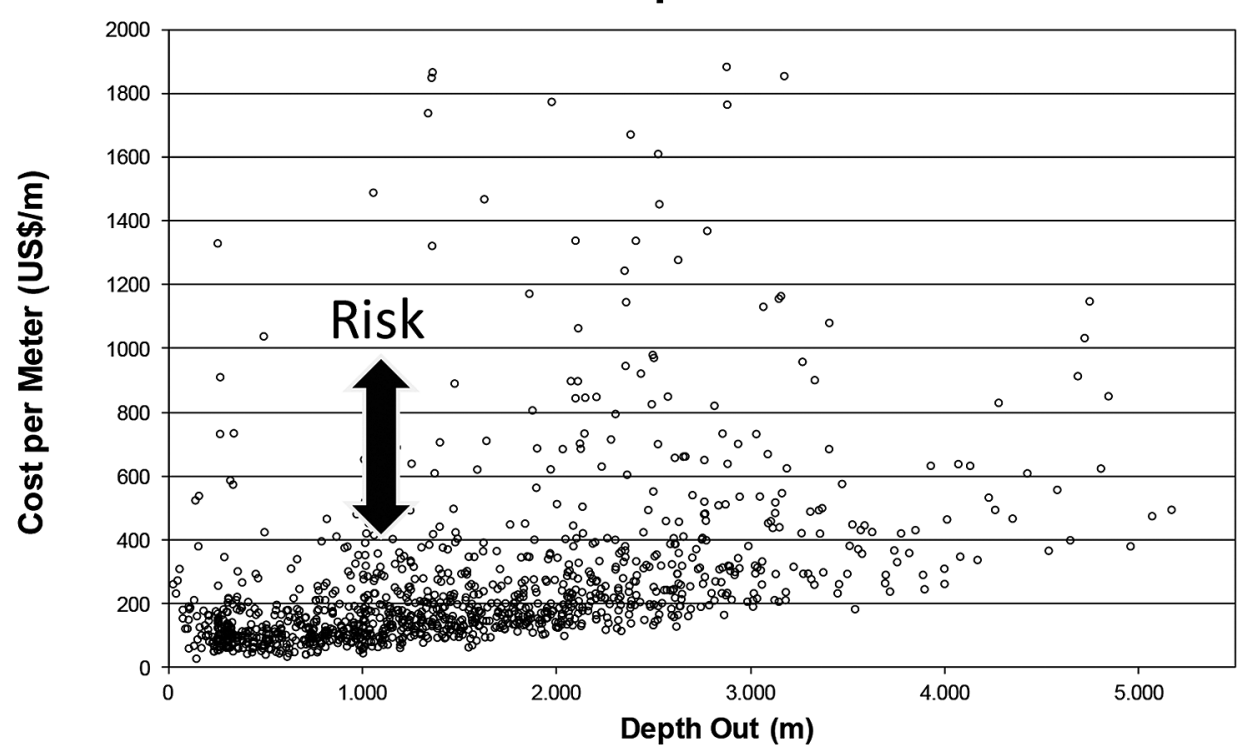

the best performances of a handful of selected results.

The measure of the goodness of the fit is improved by minimizing the sum of the squares of the deviations from the Amorim curve. By applying

$$
\text { CostSection }=\int_{\text {Depthln }}^{\text {DepthOut }} K_{1} \times e^{K_{2} \times D}
$$

the solution to the formula for any given interval. This value will be used for the the principle of Least Squares to pairs of $\left(X_{i}, Y_{i}\right)$, where $X_{i}$ is Depth Out of the bit and $\mathrm{Y}_{\mathrm{i}}$ is Cost per Meter at the end of each run (Almeida, 2015).

The Amorim Curve is the exponential equation produced by the database:

CAPEX of each well section, achieved by filtering each bit diameter in the database.

$$
\text { CostSection }=K_{1} \times\left\{\left(e^{K_{2} \times D_{2}}\right)-\left(e^{K_{2} \times D_{1}}\right)\right\} / K_{2}
$$

CM x Depth Out

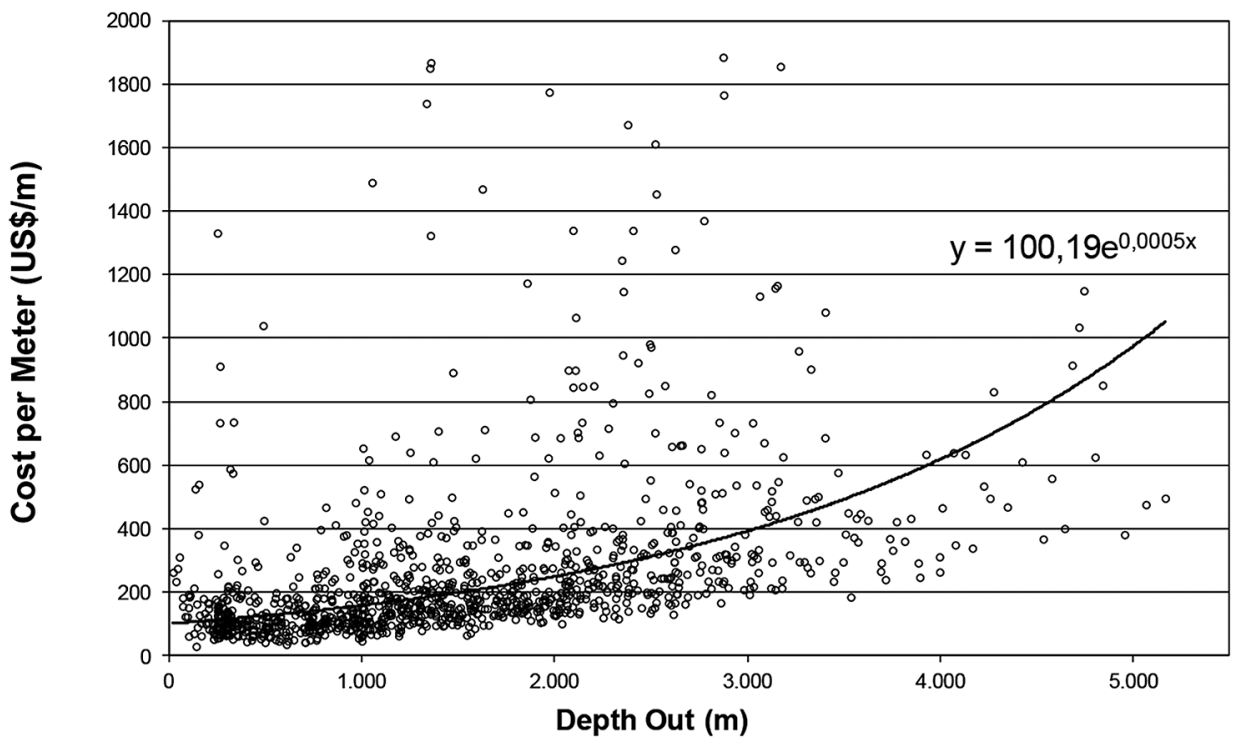




\subsection{Cost per meter of any section or bit run}

The cost per meter of any interval is determined by dividing the total cost of the interval by the length of the section. This

value is useful for planning the bit runs:

$$
C M_{\text {interval }}=\left(\int_{\text {Depthln }}^{\text {DepthOut }} K_{1} \times e^{K_{2} \times D}\right) / \mathrm{MD}
$$

\subsection{Solution for the case study}

The equation that expresses the

Amorim curve for the Pilar field, seen in

$$
C M=K_{1} \times e^{K_{2} \times D}=100.19 \times e^{0.005 \times D}
$$

The results can also be calculated and plotted in $\operatorname{Ln}(C M) \times$ Depth Out (Figure
6). Using Eq. 5 for a hypothetical interval of Depth in $=1000 \mathrm{~m}$ and Depth out $=$
Figure 5, is:

$2000 \mathrm{~m}$, the cost of the planned section can be determined with accuracy:

$$
\begin{aligned}
& \text { CostSection }=100.19 \times\left\{\left(e^{0.005 \times 2000}\right)-\left(e^{0.005 \times 1000}\right)\right\} / 0.005 \\
& \text { CostSection }=\text { US\$214,318 or } C M_{1000,2000}=U S \$ 214 / m
\end{aligned}
$$

\section{CM x Depth Out}

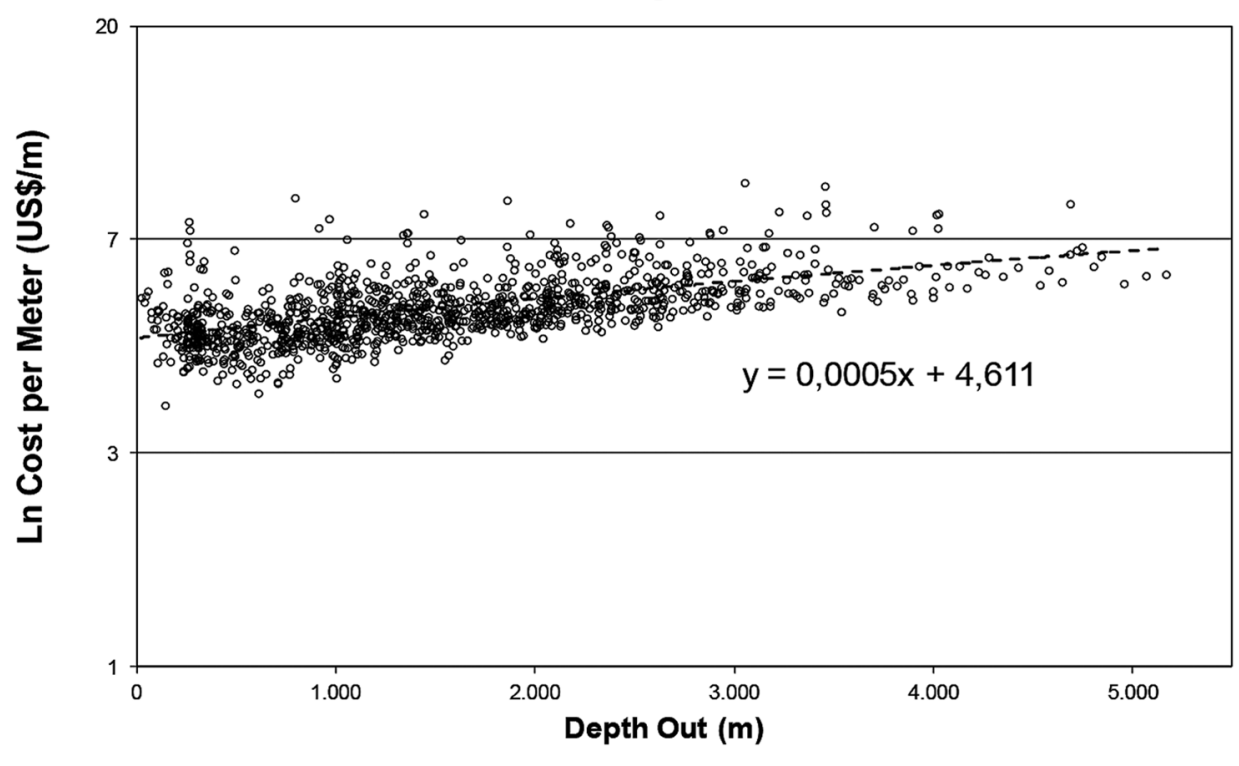

Figure 6

Ln (CM) versus Measured Depth Out for the Pilar field.

\section{Discussion: analysis of the results}

\subsection{Interpretation}

- Dots sitting on the Amorim Curve are the most probable result to happen in a future well, representing the benchmark of the existing results in the database.

- Dots below the curve are the best in class runs, desirable to be repeated in similar depth out and geological formations in the area.

- The lowest values of CM represent the Technical Limits at a depth range, within the resources used in the operation;

- Dots above the curve represent the poor performances, and the highest values of $\mathbf{C M}$ represent operations that demand investigations;

- Vertical distribution of $\mathbf{C M}$ is a graphical estimation of risk for any depth range;

- Lessons Learned for each depth range, geological formation or bit diameter can be extracted and registered in the field documents. This action will support the new project engineers, reducing the dependence of more expensive specialists;

- Reverse engineering can be applied to any desired result by entering $\mathbf{C M}$ versus depth out in the database, spotting the bit type and the operational conditions that lead to such results.

vance, being able to estimate risks and potential issues. The technical proposals can be based at predicted costs versus depth, being offered a fair bonus for a technical solution. 


\subsection{Reverse engineering for the development of solutions}

Specific filters can be applied to different drilling conditions, generating the Amorim curve achieved by each specific technology. Figure 7 shows values of CM achieved using PDC and rollercone bits in

Figure 7

Comparing performances of PDC and rollercone bits versus depth.

Examples of technical filters to work as lines of research: bit hydraulics (Ramsey, 2019); tools and procedures to

\section{Conclusion}

In the conventional planning, the personal experience of project engineer is irreplaceable in exploratory wells or in areas with lack of operational information. The planning method discussed in this article is based on statistics, and gets more precise as information is gradually gathered and processed, bringing indisputable advantages:

- Projections of future performances come from mathematical calculations;

- The most probable results are expressed by formulas of simple solution;

\section{Acknowledgements}

Our greatest appreciation for the support received from Prof. Fábio C. the Pilar field. Despite a small number of runs, PDC bits achieved two expressive results and the Technical Limits for less than 1000 meters.

Above $1000 \mathrm{~m}$, the curves reverse and PDC bits show to be uneconomical. In testing new technologies, the Amorim curve for rollercone bits for that bit diameter can be the basis of a proposal to pay a PDC bit supplier for drilling an interval.

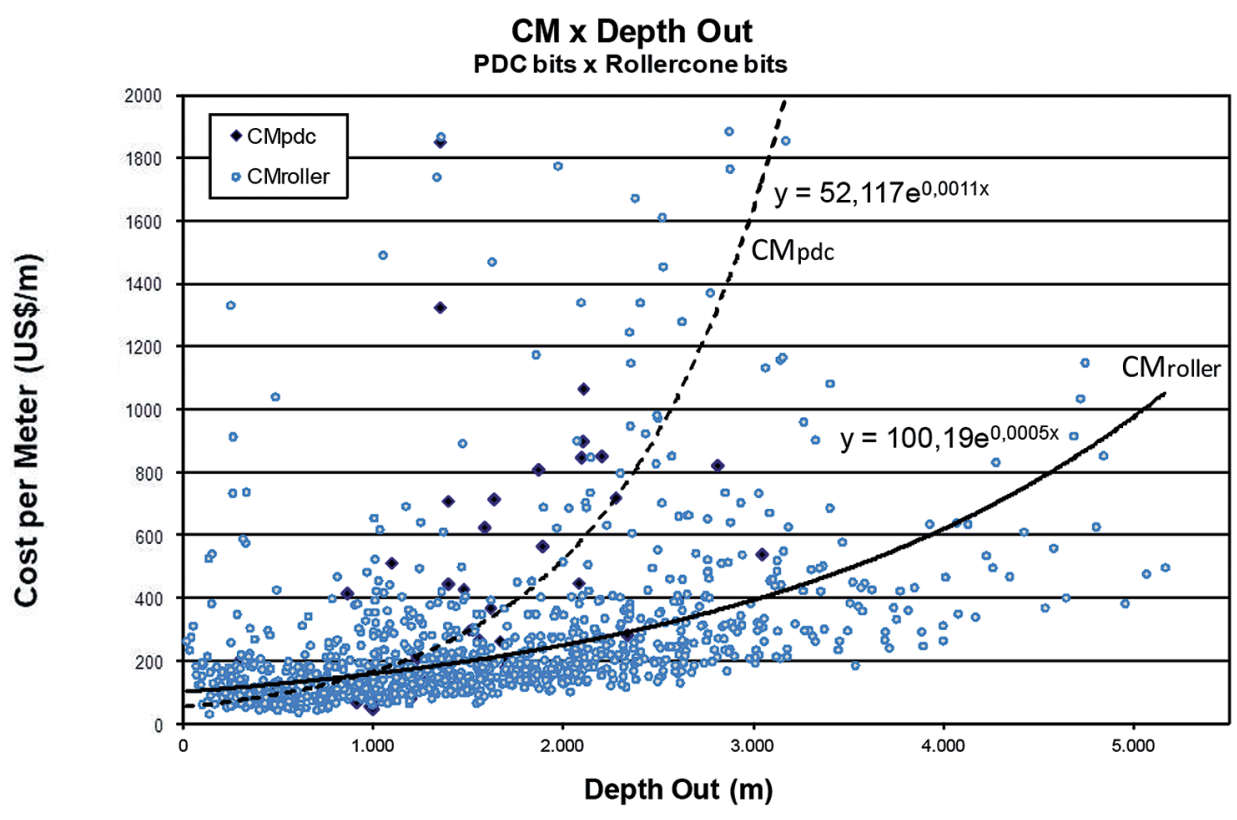

mitigate drilling vibrations (Bailey, J. et al., 2013); types of directional drilling bits and tools (Barton, S. et al., 2008); MSE (Berg
\& Tveit, 2016); drill string with roller reamers replacing stabilizers (Sowers, F. et al, 2009) etc.
- Poor performances, statistically detected to produce higher costs per meter, will support the determination of needed bit protections and operational changes;

- Manufacturers will work objectively on demands from project engineers;

- The experience of the project engineer will be useful in refining the selection of bit type and tools from the offers made by manufacturers and suppliers;

- The purchase of bits of lower prices is one of the outputs of the process.

The process discussed is a valu- able tool to support the development of solutions and improve technical limits. By applying reverse engineering, the conditions that lead to specific excellent results can be traced, repeated or overcome.

Bit manufacturers and tool suppliers will be able to present proposals supported by trustable targets and traceable conditions, receiving fair payments to develop a win-win partner relationship based on a welldefined budget.

(UVV), Professors Henrique S. Gabarra and Rodrigo Aécio Félix (UNAERP).

\section{References}

de Castro (UFES), Dr. Marcone J. Freitas (UFOP), Prof. Emanuella A. Fontan
ALMEIDA, R. O método dos mínimos quadrados: estudo e aplicações para o ensino médio. Campo dos Goytacazes, RJ, Brazil: Universidade Estadual do Norte Fluminense, 2015. p. 69. (Thesis for Master Degree).

AMORIM Jr., D. S. Otimização de custos na perfuração de poços de petróleo. São Paulo: USP, 2008.

AMORIM JR., D. S., IRAMINA, W. Manobras para troca de brocas em poços de petróleo. TN Petroleo. n. 61, p. 190-194, 2008. 
AMORIM, D., HANLEY, C., FONSECA, I., SANTOS, J., LEITE, D. J., BORELLA, A., et al. Parameter definition using vibration prediction software leads to significant drilling performance improvements. Rio Oil \& Gas. Rio de Janeiro: IBP, 2012. p. 17.

BAILEY, J., CARSTEN, E., RICHARD, J., PAUL, P., MATTHEW, P., WILLIAM, W. Design evolution of drilling tools to mitigate vibrations. In S. O. Engineers (Ed.). SPE drilling and completion. Amsterdam, Netherlands: Society of Petroleum Engineers, 2013. p. 20.

BARTON, N. The shear strength of rock and rock joints. International Journal of Rock Mechanics and Mining Sciences \& Geomechanics Abstracts, n. 13, p. 255-279, 1976.

BARTON, S. et al. Controlling torque and cutting costs: steerable drill bits deliver in Latin America. In: G. a.-I. Brazilian Petroleum (Ed.). In: RIO OIL \& GAS EXPO AND CONFERENCE 2008. Rio de Janeiro: IBP, 2008. p. 8.

BERA, P. Estimation of pore pressure from well logs: a theoretical analysis and case study from an Offshore Basin, North Sea. Hyderabad, India: 2010.

BERG, P. V., TVEIT, Ø. S. Model for evaluating drilling efficiency based on the concept of Mechanical Specific Energy. Trondheim, Norway: NTNU, Norwegian University of Science and Technology, Department of Petroleum Engineering and Applied Geophysics, 2016.

BJELM, L. Under balanced drilling and possible well bore damage in low temperature geothermal environments. 31st WORKSHOP ON GEOTHERMAL RESERVOIR ENGINEERING. Lund: Stanford University, 2006. p. 6.

BRANDON, B.D. et al. (1992). Development of a New IADC fixed cutter drill bit classification system. In: IADC/SPE (Ed.). In: IADC/SPE DRILLING CONFERENCE, IADC/SPE 23940, pp. 841-848. New Orleans, USA, 1992.

CHRISTIAN, E. Identifying the optimum zone for reducing drill string vibrations. In: SPE Annual Technical Conference and Exhibition, 9-11 October. San Antonio, Texas, USA: Society of Petroleum Engineers, 2017. p. 12.

DEVORE, J. L. Probability \& statistics for engineering and the sciences. (Eigth edition). San Luis Obispo, CA, USA: CENGAGE Learning,2010.

FREITAS, M. Métodos numéricos. In: Ajuste de curvas pelo Método dos Quadrados Minimos. Ouro Preto, MG, Brasil: Departamento de Computação, 2003. p. 5. (U. F. Preto \& I. D. BIOLÓGICAS - Ed.).

GHASEMLOONIA, A. Vibration analysis of a drillstring in vibration-assisted rotary drilling: finite element modeling with analytical validation. Journal of Energy Resources Technology, v. 135, n. 18, 2012.

KAISER, M. J. Modeling the time and cost to drill an offshore well. Energy, p. 1097-1112, 2009 May.

LEE, S. S. et alii. Development of a trip time for bit exchange simulator for drilling time. Geothermics, n. 71, p. 24-33, 2018.

McGEHEE, D. Y. et alii. The IADC Roller Bit Classification System. IADC/SPE 23937. Louisiana, USA: Society of Petroleum Engineers, 1992. p. 801-818.

RAMSEY, M. Practical Wellbore bydraulics and bole cleaning. Texas, USA: IADC, 2019. (G. P. Publishing - Ed.)

SAMUEL, R. Formulas and calculations for drilling operations. Salem, USA: Scrivener Publishing Collection Editors, 2010.

SIMMONS, E. A technique for accurate bit programming and drilling performance optimization. In: SPE/IADC DRILLING CONFERENCE. Dallas, Texas, USA: 1986, December 02.

SOWERS, F., DUPRIEST, F., BAILEY, J., WANG, L. Use of roller reamers improves drilling performance in Wells Limited by bit and bottomhole assembly vibrations. In: SPE/IADC DRILLING CONFERECE AND EXHIBITION. Amsterdam, The Netherlands: SPE, 2009 March 17-19. p. 8. (S. O. Engineers Ed.).

STEVENS, J. P. Why you need metadata for Big Data success. 2016 April 06. Retrieved 2018, from Data Science Central: https://www.datasciencecentral. com/profiles/blogs/why-you-need-metadata-for-big-data-success

VAN KAMPEN, N. G. Stochastic processes in Physics and Chemistry (Fourth Edition). Oxford, EN, England: Elsevier, 1992.

YORK, P. L., PRICHARD, D. M., DODSON, J. K., DODSON, T., 
ROSENBERG, S. M., GALA, D. et alii. Eliminating non-productive time associated with drilling through trouble zones. In: OFFSHORE TECHNOLOGY CONFERENCE. (p. 18). Houston, USA: 2009. p. 18

Received: 3 December 2018 - Accepted: 12 July 2019. 